\title{
DESAIN PENGEMBANGAN EKONOMI RUMAH TANGGA NELAYAN KABUPATEN ROKAN HILIR YANG BERKELANJUTAN DAN BERBASIS KEUNGGULAN LOKAL
}

\author{
Hazmi Arief $^{1}$, Firman Nugroho ${ }^{1}$ dan Ulfa Rizki Pradini ${ }^{2}$ \\ ${ }^{1}$ Dosen Fakultas Perikanan dan Kelautan Universitas Riau \\ ${ }^{2}$ Mahasiswa Pascasarjana Agribisnis Fakultas Pertanian Universitas Riau \\ Email: hazmi_arief@yahoo.com
}

\begin{abstract}
ABSTRAK
Penelitian ini dilaksanakan di Kabupaten Rokan Hilir pada bulan MaretSeptember 2020. Penelitian ini bertujuan untuk (1) Menganalisis kondisi eksisting dan potensi sumberdaya ikan ekonomis Kabupaten Rokan Hilir; (2) Menganalisis peran kelembagaan dan stakeholder kunci pengembangan perikanan Kabupaten Rokan Hilir; dan (3) Mengevaluasi keberlanjutan Pengembangan Ekonomi Lokal Daerah (PELD) Kabupaten Rokan Hilir. Teknik analisis data yang digunakan dalam penelitian ini adalah analisis bioekonomi, analisis kelembagaan, analisis MDS (multidimensional scaling) dan analisis prospektif. Hasil analisis menunjukkan bahwa (1) secara umum kondisi dan potensi perikanan berdasarkan analisis bioekonomi dari ketiga produk sumberdaya perikanan tangkap (udang, ikan biang, senangin), pemanfaatan sumberdaya perikanan di Kabupaten Rokan Hilir khususnya udang masih berada di bawah titik optimalnya dan merupakan salah satu produk unggulan, pengelolaan yang optimal adalah menggunakan rezim pengelolaan MEY atau Sole Owner. (2) Stakeholder primer adalah Pemerintah Daerah (Dinas Terkait), Lembaga Keuangan Mikro/Bank, Pemilik Usaha Lokal, Investor/Pengusaha Luar. (3) Status keberlanjutan pengembangan ekonomi rumah tangga nelayan yang berkelanjutan dan berbasis keunggulan lokal saat ini secara multidimensi termasuk kategori cukup berkelanjutan. Sementara itu, hasil analisis multidimensi menunjukkan bahwa Kabupaten Rokan Hilir cukup berkelanjutan $(54,45)$. Desain pengembangan ekonomi rumah tangga nelayan yang berkelanjutan dan berbasis keunggulan lokal yaitu ditemukan faktor-faktor dominan yang berpengaruh yaitu $\mathrm{P}=\mathrm{f}(\mathrm{e}, \mathrm{t}, \mathrm{l}, \mathrm{r}, \mathrm{s}, \mathrm{n}, \mathrm{y})$.
\end{abstract}

Kata kunci : Desain, ekonomi rumah tangga nelayan, kelembagaan, berkelanjutan, MDS.

\section{ABSTRACT}

This research waw conducted in District of Rokan Hilir from March until September 2020. This research purposes are (1) To analize exsisting condition and potential resource of economic fish in District of Rokan Hilir; (2) To analize role of institutions and key stakeholders development fisheries in District of Rokan Hilir; (3) To evaluate sustainability of Pengembangan Ekonomi Lokal Daerah (PELD) in District of Rokan Hilir. The method of data analysis are bioeconomic analysis, institutions analysis, MDS (multidimensional scaling) analysis and prospective analysis. The research result revealed that (1) Overall the condition and fishery potentials based on bioeconomic analysis is three resource of fishing catch (shrimp, biang and senangin), utilization of fishery resource potentials in District of Rokan Hilir especially shrimp still at below of optimum point and to be one of advanteges product, optimum 
management is using rezim of MEY management or sole owner. (2) Primary stakeholders are District government, micro financial institution/bank, owner of local business, investor. (3) Sustainabilty status developing of fisherman that sustain and based on local advantages by multidimension enough of sustainability category. Analysis of multidimension revealed that District of Rokan Hilir enough of sustainability (54,45). Development design of household fishermen economic that sustain and based local advantages find dominant factors $P=f(e, t, l, r, n, y)$

Key words :Design, fishermen household economic, institutions, sustainability, MDS.

\section{PENDAHULUAN}

Kebijakan pembangunan daerah haruslah berlandaskan pada kondisi, potensi serta keinginan masyarakat, sehingga karakteristik yang dimiliki oleh masing-masing daerah menjadi pertimbangan penting dalam perencanaan pembangunan. Perencanaan ini nantinya akan memberikan arahan dalam pengelolaan sumberdaya setiap daerah. Demikian juga halnya dengan pengembangan ekonomi rumah tangga nelayan, sehingga kebijakan yang dirumuskan dapat meningkatkan kesejahteraan masyarakat secara keberlanjutan dari berbagai aspek.

Secara sosiologis, komunitas nelayan yang berada di pesisir berbeda dari komunitas petani. Perbedaan ini disebabkan oleh adanya perbedaan antara karakteristik nelayan dan petani. Petani menghadapi situasi ekologis yang dapat dikontrol sedangkan nelayan dihadapkan pada situasi ekologis yang sulit dikontrol produksinya mengingat perikanan tangkap bersifat open access sehingga nelayan juga harus menyesuaikan dengan kondisi yang ada dan ada elemen risiko yang harus dihadapi lebih besar daripada yang dihadapi petani. Dengan demikian, nelayan dalam kondisi realitasnya, teknologi dan ketersediaan modal menjadi syarat utama yang harus dipenuhi dalam mengakses potensi lahan berupa lautan yang kaya akan sumberdaya. Selain itu beberapa permasalahan mendasar baik internal maupun eksternal menjadi faktor rendahnya tingkat ekonomi masyarakat nelayan. Kondisi ini juga terjadi pada nelayan di Kabupaten Rokan Hilir.

Pengembangan ekonomi merupakan salah satu faktor penentu keberlanjutan suatu daerah. Kabupaten Rokan Hilir memiliki sumberdaya perikanan dan non perikanan yang potensial namun secara umum kondisi ekonomi rumah tangga nelayan masih rendah. Beberapa program peningkatan ekonomi masyarakat nelayan yang dilakukan, baik oleh pemerintah maupun swasta/LSM seringkali berhenti di tengah jalan, berbagai persoalan teknis maupun non teknis menjadi penghalang berlanjutnya sebuah program /kegiatan. Latar belakang persoalan di atas menjadi titik tekan dari kajian ini, guna memberikan rekomendasi desain pengembangan dalam hal pengembangan ekonomi rumah tangga nelayan yang berkelanjutan dan berbasis keunggulan lokal. Penajaman keberlanjutan secara multidimensi dituangkan ke dalam aspek evaluasi pengembangan ekonomi lokal daerah (PELD).

Berdasarkan latar uraian tersebut penelitian ini bertujuan untuk (1) Menganalisis kondisi eksisting dan potensi sumberdaya ikan ekonomis Kabupaten Rokan Hilir; (2) Menganalisis peran kelembagaan dan stakeholder kunci pengembangan perikanan Kabupaten Rokan Hilir; dan (3) Mengevaluasi keberlanjutan 
Pengembangan Ekonomi Lokal Daerah (PELD) Kabupaten Rokan Hilir.

\section{METODOLOGI PENELITIAN}

\subsection{Lokasi dan Waktu Penelitian}

Penelitian ini dilaksanakan di Kabupaten Rokan Hilir pada bulan Maret-September 2020. Lokus kajian dilaksanakan pada 2 kecamatan terpilih dengan pertimbangan jumlah produksi perikanan yang dihasilkan dan jumlah nelayan yang mendiami kecamatan tersebut. Adapun kecamatan yang menjadi lokus penelitian antara lain; Kecamatan Pasir Limau Kapas dan Kecamatan Bangko.

\subsection{Jenis dan Metode Pengambilan Data}

Jenis data yang akan dikumpulkan meliputi data primer maupun sekunder. Data primer merupakan data pokok yang didapat langsung dari objek penelitian berupa data kualitatif yaitu data yang tidak diukur secara nominal. Data sekunder merupakan data pelengkap yang berisi hal-hal yang dapat mendukung dan berhubungan dengan data primer, berfungsi sebagai bahan arahan dan pertimbangan dalam proses komparasi. Pengumpulan data primer dilakukan dengan metode survei dengan alat bantu kuesioner yang telah dipersiapkan. Pengambilan sampel representatif dilakukan dengan menstratifikasi secara proporsional berdasarkan rumah tangga nelayan, teknik pengambilan sampel menggunakan metode purposive sampling. Informasi dari data primer dan sekunder yang dikumpulkan diperkuat dengan survei non-peluang dengan cara observasi, wawancara mendalam (indepth interview), dan caracara lain yang disesuaikan dengan kondisi responden.

\subsection{Metode Analisis}

\section{Analisis Bioekonomi}

Penilaian sumberdaya perikanan yang perlu diketahui adalah nilai estimasi tangkapan lestari dari stok ikan. Guna mengetahui nilai estimasi tangkapan lestari dilakukan estimasi dengan model kuantitatif. Produktivitas stok ikan dipengaruhi oleh faktor endogenous seperti faktor biologi, pertumbuhan, kelahiran rekruitmen, kematian dan ruaya, serta faktor exogenous seperti iklim, bencana, dan aktivitas manusia berupa penangkapan, pencemaran yang dapat menyebabkan turunnya kualitas perairan berdampak rusaknya ekosistem perairan.

Langkah-Langkah dalam pemodelan bioekonomi untuk melakukan pemodelan bioekonomi ada beberapa langkah yang perlu dilakukan (Fauzi dan Anna, 2005) :

1. Menyusun data produksi dan upaya (effort) dalam bentuk urut waktu (series). Jika menyangkut multigear multispecies, terlebih dahulu harus dipisahkan menurut jenis alat tangkap dan produksi tersebut diusahakan merupakan target spesies dari alat tangkap yang dianalisis.

2. Melakukan standarisasi alat tangkap. Langkah ini diperlukan karena ada variasi atau keragaman dari kekuatan alat tangkap.

3. Melakukan pendugaan terhadap parameter biologi dengan teknik Ordinary Least Square (OLS).

4. Melakukan estimasi parameter ekonomi berupa harga per $\mathrm{kg}$ atau per ton dan biaya memanen per trip atau per hari melaut, sebaliknya diukur dalam ukuran riil (disesuaikan dengan indeks harga konsumen) jadi harga nominal pada periode $\mathrm{t}$ (pnt), misalnya, bisa dikonversi dengan harga riil (prt) 
Analisis Kelembagaan

Analisis kelembagaan ini bertujuan untuk memotret situasi kelembagaan yang sudah ada. Menurut Ostrom et al. (1994), kelembagaan sebagai alat untuk mengarahkan, mengharmonisasikan, mensinergikan atau membatasi perilaku manusia yang cenderung mementingkan diri sendiri, opurtunis dan tidak mau bekerjasama. Fokus analisis adalah perilaku manusia yang ada dalam suatu arena aksi (masyarakat nelayan Kabupaten Rokan Hilir). Arena aksi ini meliputi situasi aksi (aktivitas masyarakat sehari-hari mencakup siapa saja yang berpartisipasi, posisinya dalam aktivitasnya, aksi atau aktivitas yang dilakukannya, apa saja yang bisa dihasilkannya dari aktifitas tersebut, serta aktor/pelaku aksi pemerintah, nelayan dan pengusaha).

\section{Analisis MDS}

Dalam rangka mengevaluasi keberlanjutan Pengembangan Ekonomi Lokal Daerah (PELD) Kabupaten Rokan Hilir, maka dilakukan analisis keberlanjutan MDS menggunakan aplikasi Raled (Rapid Assessment Techniques for Local Economic Development). Metode PELD dalam kajian ini menggunakan teknik Raled yang merupakan modifikasi dari teknik Rapfish dengan mengacu pada panduan PEL Bappenas Tahun 2007.

\section{HASIL DAN PEMBAHASAN}

Di bidang Perikanan Kabupaten Rokan Hilir memiliki daya tarik dan keunggulan untuk investasi yang meliputi segmen perikanan tangkap, budidaya dan pengolahan hasil perikanan. Hasil dari komoditi perikanan laut memiliki potensi sumber daya hayati yang dapat diperbaharui yang sangat besar.
Besarnya peluang untuk
investasi perikanan tangkap dan turunannya di Kabupaten Rokan Hilir karena didukung sumberdaya alam pesisir dan laut yang cukup besar juga tersedia sumberdaya manusia yang cukup dan berpengalaman sebagai nelayan dan cukup handal serta memiliki pangsa pasar domestik dan luar negeri.

\section{Analisis Bioekonomi Sumberdaya Perikanan}

Analisis bioekonomi sumber daya perikanan bertujuan untuk menilai tingkat pemanfaatan optimum yang melestarikan sumberdaya. Hal ini bertujuan untuk mendapatkan bentuk kebijakan yang tepat dalam pengelolaan dan pengembangan sumberdaya perikanan tangkap di Rokan Hilir. Analisis yang dilakukan dalam penelitian ini adalah pada jenis udang, ikan biang dan Senangin. Pemilihan jenis spesies tersebut sebagai objek penelitian karena merupakan komoditi utama perikanan tangkap Rokan Hilir yang menghasilkan kontribusi terbesar dibandingkan jenis lain.

Analisis bioekonomi dilakukan untuk menentukan tingkat penguasaan maksimum bagi pelaku pemanfaatan sumberdaya perikanan. Perkembangan usaha perikanan tidak hanya ditentukan dari kemampuan untuk mengeksploitasi sumberdaya ikan secara biologis saja, akan tetapi faktor ekonomi juga sangat berperan penting. Pendekatan analisis secara biologi dan ekonomi merupakan salah satu alternatif yang dapat diterapkan dalam upaya optimalisasi penguasaan sumberdaya perikanan tangkap secara berkelanjutan.

Parameter ekonomi dimasukkan dalam analisis ini agar diketahui tingkat optimal dari nilai manfaat atau rente pemanfaatan sumberdaya perikanan yang diterima oleh masyarakat nelayan. 
Sehingga pemanfaatan sumberdaya perikanan mampu mencapai tujuan akhirnya yaitu peningkatan pendapatan dan kesejahteraan masyarakat nelayan.

Tabel 1. Hasil Estimasi Parameter Biologi dan Ekonomi Sumberdaya Udang

Parameter

\begin{tabular}{ccccc}
\hline $\mathbf{r}$ (ton/trip) & $\mathbf{q}$ (ton/unit) & $\mathbf{K}$ (ton) & $\mathbf{p}$ (price, $\mathbf{j t ~ R p / t o n )}$ & $\mathbf{c}(\mathbf{c o s t}, \mathbf{j t} \mathbf{R p} /$ trip) \\
\hline 0,0817121306 & 0,0000004993 & $69.802,77$ & 13,90 & 1,26 \\
\hline
\end{tabular}

Sumber : Hasil Analisis Data, 2020

Tabel 2. Hasil Estimasi Parameter Biologi dan Ekonomi Sumberdaya Ikan Biang

\section{Parameter}

\begin{tabular}{ccccc}
\hline $\mathbf{r}$ (ton/trip) & $\mathbf{q}$ (ton/unit) & K (ton) & $\mathbf{p ~ ( p r i c e , ~ j t ~ R p / t o n ) ~}$ & c (cost, jt Rp/trip) \\
\hline 0,5489209647 & 0,0000123683 & 234,37 & 23,00 & 0,9
\end{tabular}

Sumber : Hasil Analisis Data, 2020

Tabel 3. Hasil Estimasi Parameter Biologi dan Ekonomi Sumberdaya Senangin

\begin{tabular}{ccccc}
\hline \multicolumn{5}{c}{ Parameter } \\
\hline r (ton/trip) & q (ton/unit) & K (ton) & p (price, jt Rp/ton) & c (cost, jt Rp/trip) \\
\hline 0,9594361198 & 0,0000038926 & 922,20 & 1,50 & 0,9 \\
\hline
\end{tabular}

Sumber : Hasil Analisis Data, 2020

Berdasarkan data pada Tabel 1, 2 dan 3 maka estimasi beberapa kondisi sustainable yield, yaitu MSY, Open Access dan Sole Owner dapat ditentukan. Hasil estimasi menunjukkan harga udang yang diperoleh melalui parameter ekonomi adalah $\mathrm{Rp} 13,90$ juta per ton, harga biang Rp 23 juta per ton, harga Senangin Rp 1,50 juta per ton. Sedangkan untuk biaya penangkapan udang per-trip adalah sebesar Rp 1,26 juta, biaya biang dan Senangin per tip adalah Rp 0,9 juta.

\section{Analisis Kelembagaan Usaha Perikanan}

Kelembagaan atau pranata sosial merupakan suatu sistem tata kelakuan dan hubungan yang berpusat pada aktivitas untuk memenuhi kebutuhan khusus dalam kehidupan masyarakat (Sanim, 2002). Komponen kelembagaan dalam penelitian ini terdiri atas nelayan sebagai anggota masyarakat, teknologi dan informasi perikanan, pemasaran, kelompok nelayan, permodalan, pemerintah dan aturan tidak tertulis dalam pemanfaatan sumberdaya perikanan di Rokan Hilir.

Nelayan sebagai makhluk sosial memiliki tanggung jawab dalam menjaga keutuhan sistem interaksi yang harmoni dalam masyarakat dan memberikan pegangan dalam kontrol sosial. Hasil penelitian ini membuktikan bahwa baik nelayan pendatang maupun lokal, mekanisme interaksi sosial berlangsung secara bersama-sama, dimana selain berupaya meningkatkan kesejahteraan melalui pengelolaan usaha perikanan, beberapa nelayan juga memiliki peran dalam masyarakat sebagai pengatur desanya.

\section{Analisis Stakeholder dalam Pengembangan Perikanan}

Dalam rangka membuat suatu model kebijakan terkait pengembangan ekonomi rumah tangga nelayan berkelanjutan dan berbasis keunggulan 
lokal, maka diperlukan suatu kerjasama dari berbagai pihak untuk merumuskannya.

Analisis stakeholder perlu dilakukan untuk menentukan pihakpihak yang berkompeten dalam merumuskan kebijakan tersebut. Schmeer (2007) menyatakan analisis ini merupakan proses sistematis untuk mengumpulkan dan menganalisis informasi secara kualitatif dalam menentukan kepentingan siapa yang harus diperhitungkan ketika mengembangkan atau menerapkan suatu kebijakan. Stakeholder dapat diartikan sebagai individu, kelompok atau lembaga yang kepentingannya dipengaruhi oleh kebijakan atau pihak yang tindakannya secara kuat mempengaruhi kebijakan.

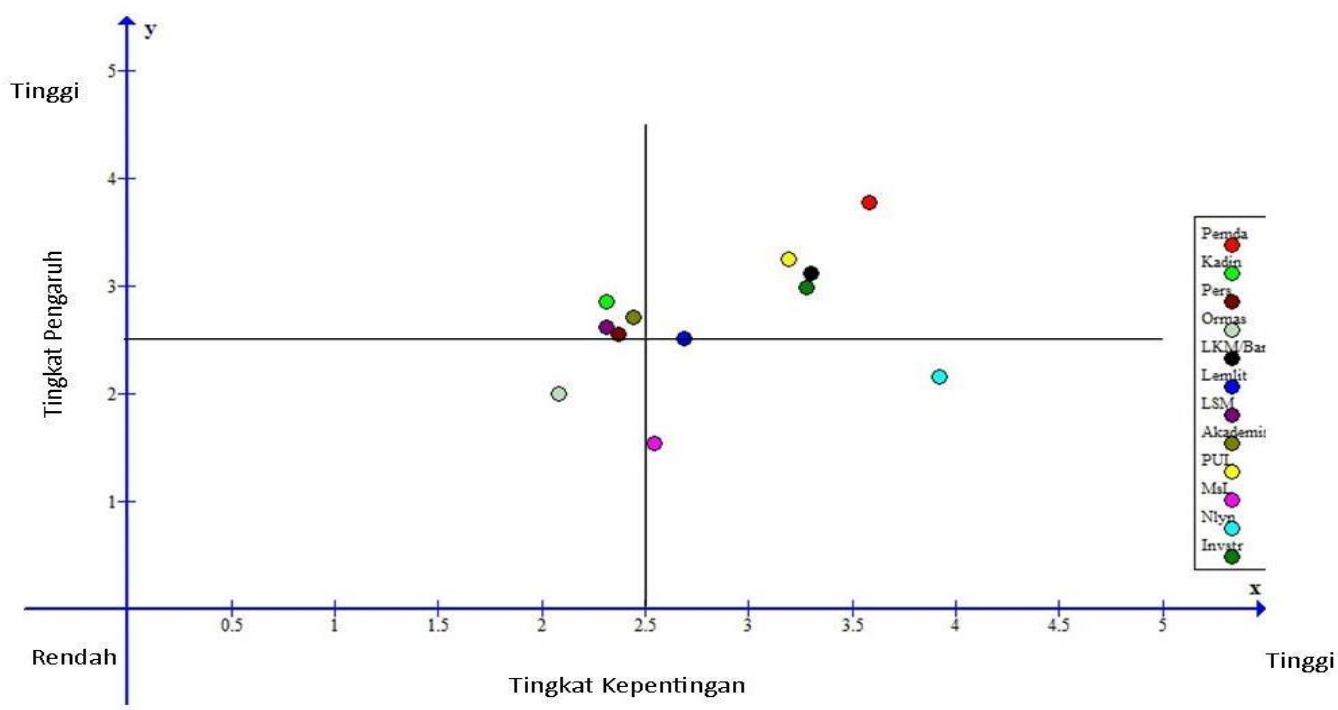

Gambar 2. Matriks Kepentingan dan Pengaruh Stakeholder dalam Pengembangan ekonomi rumah tangga nelayan berkelanjutan dan berbasis keunggulan lokal

Keterangan Stakeholder :

Pemerintah Daerah (Dinas Terkait), Perguruan tinggi, Kadin, Lembaga Swadaya Masyarakat, Nelayan, Pers/Media, Organisasi Masyarakat, Lembaga Keuangan, Lembaga Penelitian dan Pengkajian, Pemilik Usaha Lokal, nelayan, Masyarakat Lokal, Investor/Pengusaha Luar.

\section{Analisis \\ Keberlanjutan \\ Pengembangan Ekonomi Rumah \\ Tangga Nelayan Berkelanjutan dan Berbasis Keunggulan Lokal}

Analisis monte carlo merupakan serangkaian proses simulasi yang berlangsung untuk menguji pengaruh dari beragam kekeliruan (ketidakpastian), baik yang berkenaan dengan skoring maupun dalam proses ordinasi status keberlanjutan pengembangan ekonomi rumah tangga nelayan berkelanjutan dan berbasis keunggulan lokal. Menurut Law dan Kelton (2000), simulasi Monte Carlo yang umumnya statik, digunakan untuk memecahkan permasalahan stokastik atau deterministik tertentu. Tabel 4 menyajikan perbandingan indeks keberlanjutan hasil MDS dengan hasil analsis Monte Carlo. 
Tabel 4. Perbandingan Indeks Keberlanjutan Hasil MDS dan Monte Carlo (Selang Kepercayaan $95 \%)$

\begin{tabular}{|c|c|c|c|}
\hline Aspek & MDS & Monte Carlo & Selisih \\
\hline Aspek Usaha Perikanan & 62,09 & 61,14 & 0,95 \\
\hline Aspek Faktor Lokasi & 52,49 & 52,53 & 0,04 \\
\hline $\begin{array}{l}\text { Aspek Kesinergian dan Fokus } \\
\text { Kebijakan }\end{array}$ & 50,65 & 50,60 & 0,05 \\
\hline Aspek Perikanan Berkelanjutan & 63,22 & 62,27 & 0,95 \\
\hline Aspek Tata Pemerintahan & 53,04 & 53,01 & 0,003 \\
\hline $\begin{array}{l}\text { Aspek Proses Proses Manajemen } \\
\text { dan Kelembagaan }\end{array}$ & 45,199 & 45,69 & 0,49 \\
\hline
\end{tabular}

Sumber : Hasil Analisis Data, 2020

Hasil perbandingan antara analisis monte carlo dengan selang kepercayaan 95 persen dan analisis MDS (Tabel 4) menunjukkan bahwa nilai indeks keberlanjutan yang didapat pada setiap aspek tidak banyak mengalami perbedaan $(<1)$. Kecilnya perbedaan ini mengindikasikan bahwa; (1) kesalahan dalam pembuatan skor pada setiap atribut relatif kecil, (2) ragam pemberian skor akibat perbedaan opini relatif kecil, (3) proses analisis yang dilakukan secara berulang stabil, dan (4) kesalahan pemasukkan data dan data yang hilang dapat dihindari. Dengan demikian diketahui bahwa hasil analisis keberlanjutan yang dilakukan dengan teknik Rafed untuk pengembangan ekonomi rumah tangga nelayan berkelanjutan dan berbasis keunggulan lokal memiliki tingkat kepercayaan yang tinggi.

\section{Status Keberlanjutan Pengembangan Ekonomi Rumah Tangga Nelayan Keberlanjutan dan Berbasis Keunggulan Lokal Multidimensi}

Prediksi status keberlanjutan pengembangan ekonomi rumah tangga nelayan berkelanjutan dan berbasis keunggulan lokal digambarkan melalui 77 atribut. Seluruh atribut ini terdiri atas tiga belas atribut dalam aspek usaha perikanan, tujuh belas atribut aspek faktor lokasi, enam belas atribut aspek kesinergian dan fokus kebijakan, sembilan atribut aspek perikanan berkelanjutan, sembilan atribut aspek tata pemerintahan dan tiga belas atribut aspek proses manajemen dan kelembagaan. Dengan melakukan analisis MDS maka diketahui posisi atau status keberlanjutan lingkungan hidup pada ordinasi good atau bad.

Indeks keberlanjutan setiap aspek belum menggambarkan status keberlanjutan dari kegiatan secara keseluruhan. Untuk itu nilai indeks setiap aspek/dimensi perlu digabungkan untuk menentukan nilai status keberlanjutan multidimensi. Berdasarkan jumlah nilai tersebut maka didapatkan nilai indeks multidimensi 54,45 yang menunjukkan bahwa status keberlanjutan multidimensi pengembangan ekonomi rumah tangga nelayan berkelanjutan dan berbasis keunggulan lokal Kabupaten Rokan Hilir berada dalam kategori cukup berkelanjutan. Hal ini mengindikasikan bahwa untuk meningkatkan status keberlanjutan kegiatan secara menyeluruh diperlukan penataan terhadap berbagai atribut yang sensitivitasnya tinggi khususnya pada aspek faktor lokasi serta kesinergian dan fokus kebijakan. Status ini memiliki peran penting dalam monitoring, pengkajian serta pemahaman kondisi ekosistem, dampak kegiatan manusia, serta efektivitas kebijakan mencapai 
tujuan pengelolaan (Rice dan Rochet, 2005).

\section{Desain Pengembangan Ekonomi Rumah Tangga Nelayan Kabupaten Rokan Hilir yang Berkelanjutan dan Berbasis Keunggulan Lokal}

Desain pengembangan ekonomi rumah tangga nelayan Kabupaten Rokan Hilir yang berkelanjutan dan berbasis keunggulan lokal adalah bentuk kajian studi kasus dalam mencari desain pengembangan ekonomi perikanan bagi rumah tangga nelayan terbaik pada wilayah yang berada di pesisir Kabupaten Rokan hilir Provinsi Riau dengan perairan menghadap Selat Malaka. Ciri khas lokasi wilayah secara geografis maupun geologis menjadi ciri khas dari pemodelan pada kawasan ini. Potensi perikanan daerah ini berupa potensi perikanan tangkap (laut) dan perairan umum.

\section{Skenario Minimal (Skenario 1)}

Status keberlanjutan pengembangan ekonomi rumah tangga nelayan berkelanjutan dan berbasis keunggulan lokal dapat ditingkatkan melalui perbaikan faktor-faktor (atribut) kunci yang berpengaruh terhadap peningkatan status pengelolaan. Pada skenario 1 ini, diupayakan perbaikanperbaikan seadanya atau dengan kata lain perbaikan yang dilakukan didasarkan pada waktu dan efisiensi biaya yang dikeluarkan dapat ditekan sekecil mungkin.

Tabel 5. Perubahan Nilai Indeks Keberlanjutan Skenario 1

\begin{tabular}{llcc}
\hline No & \multicolumn{1}{c}{ Dimensi/Aspek PEP } & $\begin{array}{c}\text { Nilai Indeks } \\
\text { Eksisting }\end{array}$ & $\begin{array}{c}\text { Indeks } \\
\text { Skenario 1 }\end{array}$ \\
\hline 1 & Usaha Perikanan & 62,09 & 68,30 \\
2 & Faktor Lokasi & 52,49 & 52,49 \\
3 & Kesinergian dan Fokus Kebijakan & 50,65 & 50,65 \\
4 & Perikanan Berkelanjutan & 63,22 & 69,54 \\
5 & Tata Pemerintahan & 53,04 & 53,04 \\
6 & Proses Manajemen dan Kelembagaan & 45,20 & 45,20 \\
\hline
\end{tabular}

Dari Tabel 5 terlihat bahwa adanya peningkatan indeks keberlanjutan pada beberapa dimensi yang dilakukan perbaikan, termasuk nilai indeks multidimensi. Walaupun nilai indeks keberlanjutan pada semua dimensi berada pada status cukup berkelanjutan, upaya perbaikan atribut-atribut kunci perlu tetap dilanjutkan secara maksimal untuk masa yang akan datang. Dukungan kebijakan pemerintah yang kuat dan secara terpadu, baik pemerintah pusat, pemerintah provinsi, maupun pemerintah kabupaten sangat diperlukan, sehingga pengembangan ekonomi rumah tangga nelayan berkelanjutan dan berbasis keunggulan lokal di Kabupaten Rokan Hilir. Skenario Optimal (Skenario 2)
Pada skenario Optimal (skenario 2) ini diupayakan perbaikan atributatribut kunci yang lebih optimal, dimana $50 \%$ atribut kunci dilakukan perbaikan. Hal ini didasarkan pada pertimbangan bahwa pengembangan ekonomi rumah tangga nelayan berkelanjutan dan berbasis keunggulan lokal seharusnya dilakukan secara bertahap dengan tetap mempertimbangkan kemampuan biaya yang tersedia. Dengan dasar pertimbangan ini, akan berimplikasi pada pencapaian pengembangan ekonomi rumah tangga nelayan berkelanjutan dan berbasis keunggulan lokal yang ideal dalam waktu yang lebih cepat sulit untuk direalisasikan. 
Tabel 6. Perubahan Nilai Indeks Keberlanjutan Skenario 2

\begin{tabular}{clcc}
\hline No & \multicolumn{1}{c}{ Dimensi/Aspek PEP } & Nilai Indeks Eksisting & $\begin{array}{c}\text { Indeks } \\
\text { Skenario 2 }\end{array}$ \\
\hline 1 & Usaha Perikanan & 62,09 & 68,30 \\
2 & Faktor Lokasi & 52,49 & 52,49 \\
3 & Kesinergian dan Fokus Kebijakan & 50,65 & 50,65 \\
4 & Perikanan Berkelanjutan & 63,22 & 69,54 \\
5 & Tata Pemerintahan & 53,04 & 59,82 \\
6 & Proses Manajemen dan Kelembagaan & 45,20 & 51,98 \\
\hline
\end{tabular}

Pada Tabel 6 terlihat bahwa semua perbaikan dilakukan terhadap semua dimensi memiliki nilai indeks atribut-atribut kunci. Dengan perbaikan keberlanjutan di atas $50 \%$ atau sudah ini tentunya dibutuhkan biaya yang berada pada status cukup berkelanjutan. besar dan waktu yang cukup lama. Namun untuk mencapai kondisi yang Dalam hal ini dapat dilakukan dalam ideal, upaya peningkatan nilai indeks ini tiga masa waktu yaitu jangka pendek masih dapat dilakukan dengan dengan melakukan perbaikan-perbaikan memaksimalkan perbaikan sebagian atribut yang mendesak untuk ditangani, besar atribut kunci yang yang ada. kemudian jangka menengah dan jangka Penanganan atribut-atribut tersebut panjang dengan melakukan perbaikan dapat dilakukan seperti pada skenario 3 terhadap atribut penunjang dengan melakukan perbaikan sebagian pengembangan ekonomi rumah tangga besar atribut-atribut kunci tersebut. nelayan berkelanjutan dan berbasis

Skenario Maksimal (Skenario 3) keunggulan lokal.

Pada skenario 3 ini, upaya

Tabel 7. Perubahan Nilai Indeks Keberlanjutan Skenario 3

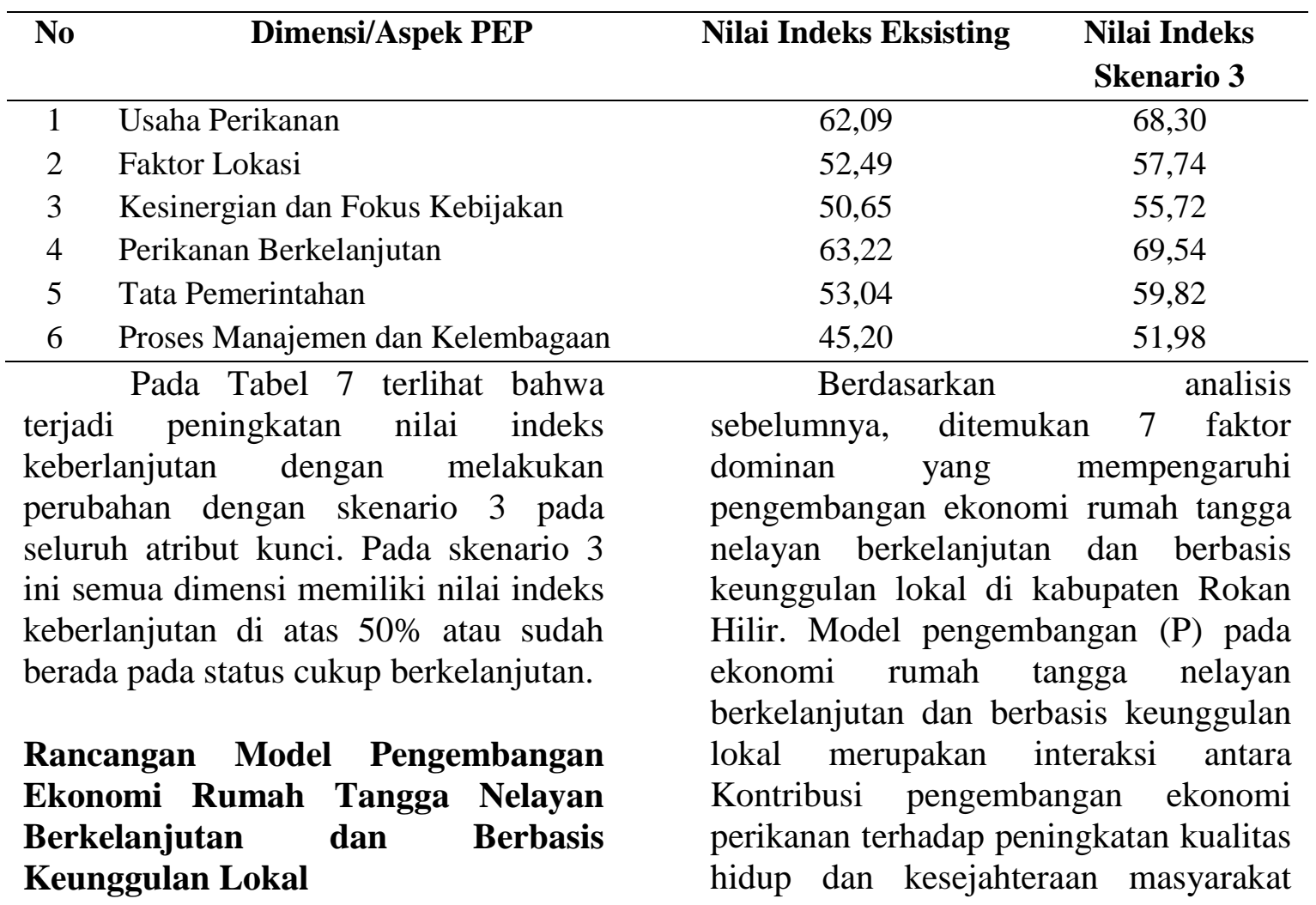


lokal (e), Reformasi sistem insentif Pengembangan SDM Aparatur (t), Jumlah stakeholder yang terlibat dalam proses perencanaan pengembangan ekonomi perikanan (1), Faktor kebijakan pemerintah (r), Ketersediaan SDM (s), Sarana dan prasarana perikanan (n), serta Pendapatan masyarakat (y) yang dapat digambarkan dalam hubungan fungsi sebagai berikut :

$$
\mathrm{P}=\mathrm{f}(\mathrm{e}, \mathrm{t}, \mathrm{l}, \mathrm{r}, \mathrm{s}, \mathrm{n}, \mathrm{y})
$$

Untuk mewujudkan fungsi

tersebut dilakukan dengan cara memperbaiki dan meningkatkan pengelolaan faktor-faktor kunci dalam pengembangan ekonomi rumah tangga nelayan berkelanjutan dan berbasis keunggulan lokal. Model pengembangan ekonomi rumah tangga nelayan berkelanjutan dan berbasis keunggulan lokal berbasis sumberdaya lokal di Kabupaten Rokan Hilir dilakukan berdasarkan atas rekomendasi yang disusun pada skenario I (minimal), II (optimal) dan III (maksimal). Pendekatan integratif Kontribusi pengembangan ekonomi perikanan terhadap peningkatan kualitas hidup dan kesejahteraan masyarakat lokal (e), Reformasi sistem insentif
Pengembangan SDM Aparatur (t), Jumlah stakeholder yang terlibat dalam proses perencanaan pengembangan ekonomi perikanan (1), Faktor kebijakan pemerintah (r), Ketersediaan SDM (s), Sarana dan prasarana perikanan (n), serta Pendapatan masyarakat (y) dalam hubungan fungsi $P=f(e, t, 1, r, s, n, y)$ menjadi pertimbangan dalam penentuan pengelolaan ekonomi rumah tangga nelayan berkelanjutan dan berbasis keunggulan lokal.

\section{Rekomendasi Kebijakan}

Berdasarkan hasil MDS, leverage, analisis kebutuhan (need analysis) dan analisis prospektif dapat diformulasikan skenario pengembangan ekonomi rumah tangga nelayan berkelanjutan dan berbasis keunggulan lokal di Kabupaten Rokan Hilir. Adapun nilai indeks keberlanjutan pada masing-masing skenario selengkapnya disajikan pada Tabel 8. Tabel 8. Nilai indeks keberlanjutan kondisi eksisting dan skenario 1, 2, 3 pengembangan ekonomi rumah tangga nelayan berkelanjutan dan berbasis keunggulan lokal di Kabupaten Rokan Hilir.

Tabel 8. Nilai Indeks Keberlanjutan Masing-Masing Skenario

\begin{tabular}{|c|c|c|c|c|c|}
\hline \multirow{2}{*}{$\begin{array}{l}\mathbf{N} \\
\mathbf{0}\end{array}$} & \multirow{2}{*}{$\begin{array}{c}\text { Dimensi/Aspek } \\
\text { PEP }\end{array}$} & \multicolumn{4}{|c|}{ Nilai Indeks Keberlanjutan } \\
\hline & & Eksisting & $\begin{array}{c}\text { Skenario } \\
\text { I }\end{array}$ & $\begin{array}{l}\text { Skenario } \\
\text { II }\end{array}$ & $\begin{array}{l}\text { Skenario } \\
\text { III }\end{array}$ \\
\hline 1 & Usaha Perikanan & 62,09 & 68,30 & 68,30 & 68,30 \\
\hline 2 & Faktor Lokasi & 52,49 & 52,49 & 52,49 & 57,74 \\
\hline 3 & Kesinergian dan Fokus Kebijakan & 50,65 & 50,65 & 50,65 & 55,72 \\
\hline 4 & Perikanan Berkelanjutan & 63,22 & 69,54 & 69,54 & 69,54 \\
\hline 5 & Tata Pemerintahan & 53,04 & 53,04 & 59,82 & 59,82 \\
\hline 6 & $\begin{array}{l}\text { Proses Manajemen dan } \\
\text { Kelembagaan }\end{array}$ & 45,20 & 45,20 & 51,98 & 51,98 \\
\hline $\begin{array}{l}\text { peng } \\
\text { nela } \\
\text { keur } \\
\text { Hilin }\end{array}$ & $\begin{array}{l}\text { Tingkat } \\
\text { embangan ekonomi rumah tangga } \\
\text { yan berkelanjutan dan berbasis } \\
\text { ggulan lokal di Kabupaten Rokan } \\
\text { dapat ditingkatkan dari kondisi } \\
\text { ting saat ini. Dengan melakukan }\end{array}$ & & $\begin{array}{l}\text { bahan pac } \\
\text { setiap } \\
\text { ngkatkan } \\
\text { rlanjutan. } \\
\text { elolaan de } \\
\text { dan } 3 \text { aka }\end{array}$ & $\begin{array}{l}\text { atribut } \mathrm{kl} \\
\text { mensi a } \\
\text { nilai } \\
\text { Melalu } \\
\text { an pener } \\
\text { liperoleh }\end{array}$ & $\begin{array}{r}\text { (sensitif) } \\
\text { mampu } \\
\text { indeks } \\
\text { strategi } \\
\text { skenario } \\
\text { tu tingkat }\end{array}$ \\
\hline
\end{tabular}


pengembangan ekonomi rumah tangga nelayan berkelanjutan dan berbasis keunggulan lokal di Kabupaten Rokan Hilir yang berkelanjutan dari masingmasing dimensi. Peningkatan nilai indeks keberlanjutan pada skenario 3 memberikan perubahan terbesar pada tingkat keberlanjutan pengembangan ekonomi rumah tangga nelayan

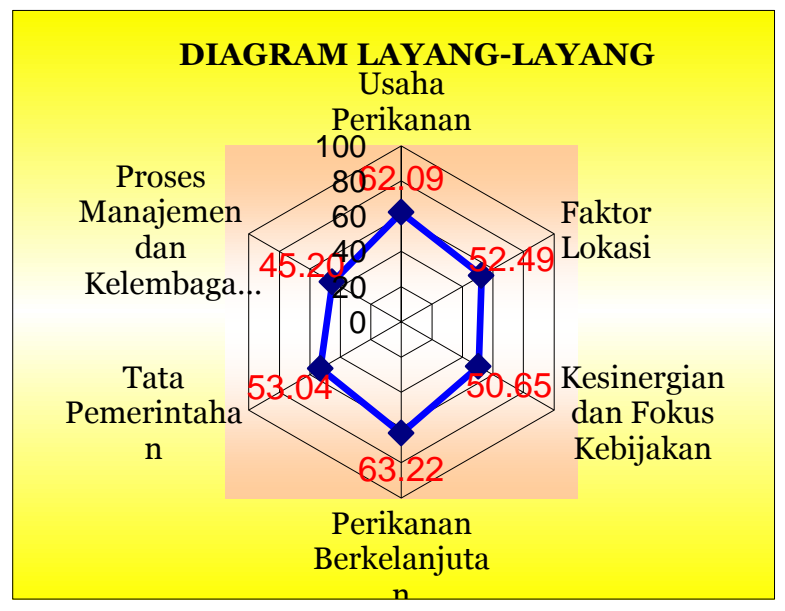

Kondisi Eksisting

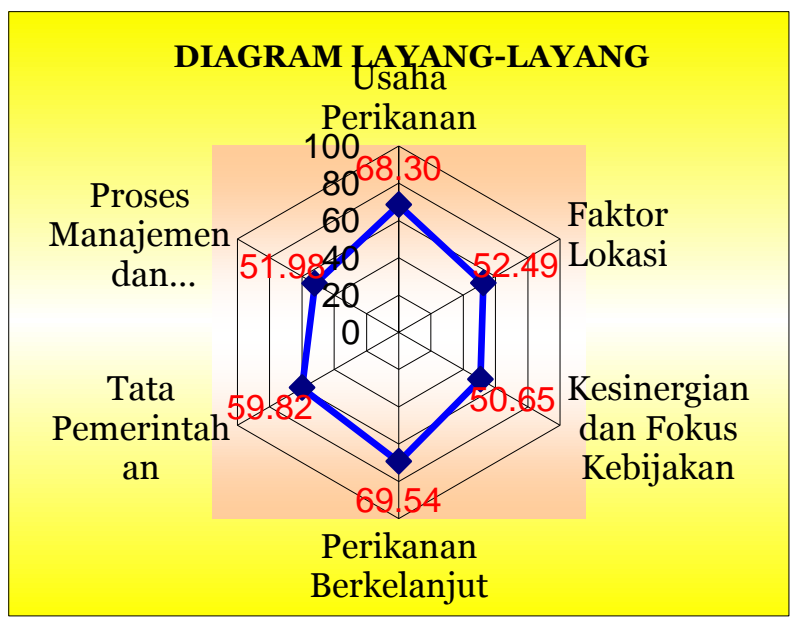

Skenario 2 berkelanjutan dan berbasis keunggulan lokal di Kabupaten Rokan Hilir.

Peningkatan nilai indeks keberlanjutan pada masing-masing skenario pada setiap dimensi keberlanjutan berdasarkan diagram layang-layang selengkapnya disajikan pada Gambar 1.

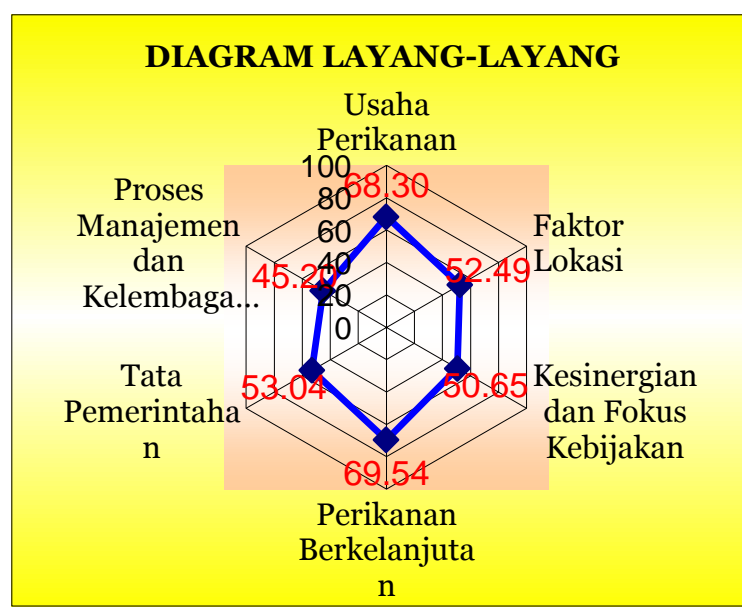

Skenario 1

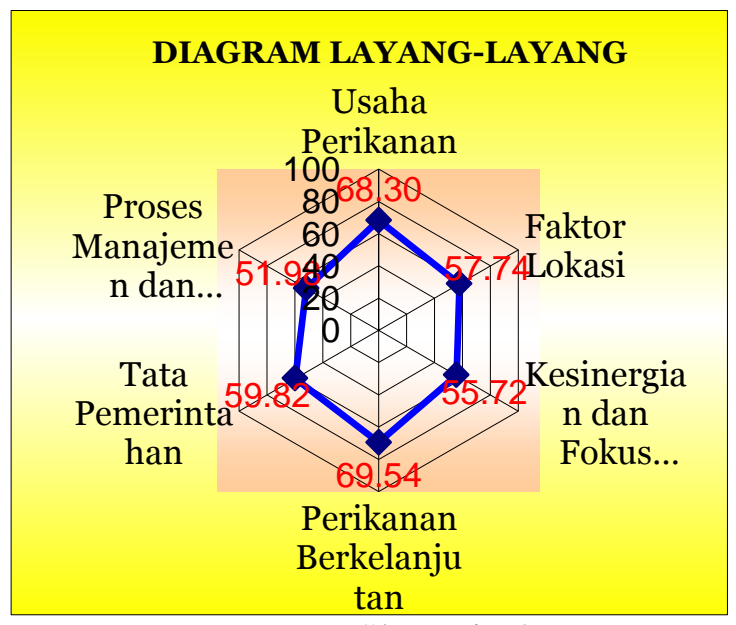

Skenario 3

Gambar 1. Nilai Indeks Keberlanjutan Lima Dimensi Keberlanjutan pada Kondisi Eksisting, Skenario 1, 2 dan 3

\section{KESIMPULAN}

Berdasarkan uraian di atas, dapat disimpulkan sebagai berikut:

1. Secara umum kondisi dan potensi perikanan berdasarkan analisis bioekonomi dari ketiga produk sumberdaya perikanan tangkap (udang, ikan biang, senangin), 
pemanfaatan sumberdaya perikanan di Kabupaten Rokan Hilir khususnya udang masih berada di bawah titik optimalnya dan merupakan salah satu produk unggulan,

2. Pengelolaan yang optimal adalah menggunakan rezim pengelolaan MEY atau Sole Owner. Stakeholder primer adalah Pemerintah Daerah (Dinas Terkait), Lembaga Keuangan Mikro/Bank, Pemilik Usaha Lokal, Investor/Pengusaha Luar.

3. Status keberlanjutan pengembangan ekonomi rumah tangga nelayan yang berkelanjutan dan berbasis keunggulan lokal saat ini secara multidimensi termasuk kategori cukup berkelanjutan. Sementara itu, hasil analisis multidimensi menunjukkan bahwa Kabupaten Rokan Hilir cukup berkelanjutan $(54,45)$.

4. Desain pengembangan ekonomi rumah tangga nelayan yang berkelanjutan dan berbasis keunggulan lokal yaitu ditemukan faktor-faktor dominan yang berpengaruh yaitu $\mathrm{P}=\mathrm{f}(\mathrm{e}, \mathrm{t}, \mathrm{l}, \mathrm{r}, \mathrm{s}$, $\mathrm{n}, \mathrm{y}$ ).

\section{UCAPAN TERIMAKASIH}

Ucapan terima r $\begin{array}{r}\text { kasih } \\ \text { disampaikan kepada }\end{array}$ Lembaga
Penelitian dan Pengabdian Masyarakat
(LPPM) Universitas Riau dalam
pelaksanaan penelitian ini, para
Reviewer, serta pihak-pihak yang telah
membantu hingga selesainya
penyusunan karya ilmiah ini.

\section{DAFTAR PUSTAKA}

Alder, J., T. J. Pitcher, D. Preikshot, K. Kaschner, and B. Ferris. 2000. How Good is Good? A Rapid Appraisal Technique for Evaluation of the Sustainability
Status of Fisheries of The Nort Atlantic. 136- $182 \mathrm{p}$.

Bappenas. 2007. Manual Penentuan Status dan Pengungkit PEL. Direktorat Perekonomian

Daerah. Badan Perencanaan Pembangunan Nasional. Jakarta.

COREMAP. 2006. Laporan Akhir Studi Pengembangan Mata Pencaharian Alternatif di Kabupaten

Selayar, Sulawesi Selatan. PT. Setia Guna Dharma. Project Management Unit, COREMAP Tahap II Kabupaten Selayar.

Charles AT., Boyd H, Lavers A, Benjamin C. 2002. Measuring sustainable development application of the genuine progress index to nova scotia Management.

Science/Environmental Studies. Saint Mary's University. Halifax

Fauzi A, S. Anna. 2015. Pemodelan Sumberdaya Perikanan dan Kelautan. PT.Gramedia Pustaka Utama. Jakarta.

[FAO] Food and Agriculture Organization. 2008. Fisheries and Aquaculture Circular No. 1034: A Review On Culture, Production and Use of Spirulina as Food For Humans and Feeds For Domestic Animals and Fish. Rome : ISBN 978-92-5106106-0

Glasson J. 1990. Pengantar Perencanaan Regional. Paul Sitohang, Penerjemah; Jakarta: LPFEUI.

Glavic P, Lukman R. 2007. Review of Sustainability Terms and Their Definitions. Journal of Cleaner Production (15): 1875 - 1885. 
Hidayat, S. 2011. Model Ekonomi Kerakyatan. Penebar Swadaya. Jakarta.

Kavanagh and Pithcher. 2001. Rapid Appraisal of Fisheries (RAPFISH) Project. University of British Columbia. Fisheries Centre.

Kavanagh P, Pitcher TJ. 2004. Implementing Microsoft Excel Software For Rapfish: A Technique For The Rapid Appraisal of Fisheries Status. [Fisheries Centre Research Reports 12(2)]. Vancouver, Canada: The Fisheries Centre, University of British Columbia.

Ostrom E et al. 1994. Rules, Games and Common-pool Resources. USA: The University of Michigan Press
Suharto, E. 2005. Membangun Masyarakat Memberdayakan Rakyat, Kajian Strategis Kesejahteraan Sosial dan Pekerjaan Sosial. Bandung: Refika Aditama.

Susilo SB. 2003. Keberlanjutan Pembangunan Pulau-pulau Kecil : Studi Kasus Kelurahan Pulau Panggang dan Pulau Pari, Kepulauan Seribu, DKI Jakarta [Disertasi]. Bogor (ID): Institut Pertanian Bogor.

Suwondo. 2011. Model Pengelolaan Lahan Gambut Berbasis Sumberdaya Lokal pada Agroekologi Perkebunan Kelapa Sawit. [Disertasi]. Bogor. Program Pascasarjana. Institut Pertanian Bogor. 434 hal. 